\title{
A ATUAÇÃO LIMITADORA DO PODER DE POLÍCIA DA ADMINISTRAÇÃO PÚBLICA EM BENEFÍCIO DO BEM-ESTAR COLETIVO
}

\author{
Patrícia Verônica Nunes Carvalho Sobral de Souza ${ }^{1}$ \\ Ricardo Maurício Freire Soares ${ }^{2}$
}

\begin{abstract}
RESUMO
Este artigo discute aspectos relevantes do poder de polícia da Administração Pública Brasileira, examinando sua atuação limitadora, conforme determina a Carta Magna. O principal escopo deste trabalho é demonstrar a restrição dos direitos individuais pelo Poder de Polícia, em prol do bem-estar coletivo. Fez-se uma breve exposição das noções introdutórias da Administração Pública. Realizou-se uma descrição evolutiva do Poder de Polícia, abordando conceitos, características, fundamentação legal e princípios norteadores. Por fim, foram apresentadas restrições impostas a este Poder, como meio de promoção da efetividade do interesse coletivo.
\end{abstract}

Palavras-chave: Administração Pública. Interesse Coletivo. Limitação. Poder de Polícia. Princípios.

\section{THE LIMITED OPERATION OF THE POLICE POWER OF THE PUBLIC ADMINISTRATION IN BENEFIT OF THE COLLECTIVE WELL BEING}

\begin{abstract}
This article discusses relevants aspects of the Brazilian Public Administration's police power, examining its limiting acting, as set forth in the Magna Carta. The main scope of this work is to demonstrate the restriction of individual rights by the Police Power, in favor of collective well-being. The introductory notions of Public Administration were briefly covered. An evolving description of the Power of Police was carried out, addressing concepts, characteristics, legal basis and guiding principles. Lastly, restraints imposed on this Power were approached as means of fostering the effectiveness of collective interest.
\end{abstract}

\footnotetext{
${ }^{1}$ Doutora em Educação e Mestra em Direito pela Universidade Federal de Sergipe (UFS). Doutoranda em Direito Público (UFBA). Especialista em Direito do Estado e Especialista em Direito Municipal (UNIDERP). Especialista em Direito Civil e Processo Civil pela Universidade Tiradentes (UNIT). Especialista em Auditoria Contábil pela Universidade Federal de Sergipe (UFS). Professora de Graduação e Pós-graduação da Universidade Tiradentes (UNIT). Diretora Técnica do Tribunal de Contas do Estado de Sergipe. E-mail: patncss@gmail.com.

${ }^{2}$ Pós-Doutor em Direito pela Università degli Studi di Roma La Sapienza, pela Università degli Studi di Roma Tor Vergata e pela Università del Salento. Doutor em Direito pela Università del Salento. Doutor em Direito Público e Mestre em Direito Privado pela Universidade Federal da Bahia. Professor dos Cursos de Graduação e Pós-Graduação em Direito da Universidade Federal da Bahia (Especialização/Mestrado/Doutorado). Professor da Universidade Católica do Salvador, da Faculdade Baiana de Direito e da Faculdade Ruy Barbosa. Professorvisitante em diversas Instituições, tais como: Università degli Studi di Roma La Sapienza, Università degli Studi di Roma Tor Vergata, Università degli Studi di Roma Tre, Università degli Studi di Milano, Università di Genova, Università di Pisa, Università del Salento, Universidade Autônoma de Lisboa, Universidade do Algarve, Universidad de Burgos e Martin-Luther- Universitat. Professor do Curso Brasil Jurídico, do Curso Damásio Educacional, da Escola Judicial do Tribunal Regional do Trabalho, da Escola de Magistrados da Bahia e da Fundação Faculdade de Direito. E-mail: ric.mauricio@ig.com.br.
} 
Keywords: Public Administration. Collective Interest. Limitation. Police Power. Principles.

\section{INTRODUÇÃO}

A Administração Pública é a reunião de órgãos, serviços e agentes pertencentes ao Estado, que detêm como finalidade garantir a concretude dos anseios sociais, entre os mais importantes: a saúde, a educação, a segurança e o bem-estar da sociedade.

Desde o momento que o cidadão iniciou sua vivência em coletividade, surgiram os conflitos sociais, visto que ocorreu a passagem da atuação pautada no interesse individual para a efetividade do interesse público. Por tal motivo, emergiu a necessidade de elaboração de normas e sanções para a concretização e o alcance da harmonia social, através da criação de leis direcionadas ao coletivo e não apenas para o interesse particular.

Neste cenário, a evolução da Administração Pública ocorreu por meio de um processo de aprimoramento de serviços a serem prestados pela máquina estatal. Ademais, em relação à garantia dos direitos individuais, existem duas óticas que expõem o conflito entre a potência da Administração Pública e a liberdade de cada indivíduo. A primeira possui a competência para restringir a execução dos direitos individuais dos cidadãos em prol do bem-estar coletivo e a segunda, por sua vez, é por onde o indivíduo anseia efetivar os seus direitos.

Decerto, órgãos criados pela Administração Pública, para controlar os atos do cidadão, são competentes para condicionar o direito individual perante o objetivo social e, entre os poderes de tais órgãos e entes está o abordado por este artigo: o poder de polícia.

Assim, a finalidade do Estado é equilibrar o interesse social ao direito individual, sem obstar este. Todavia, o Estado deve limitar os direitos e liberdades integrais em prol do interesse coletivo, observando que o princípio da supremacia do interesse coletivo sobre o particular deve ser o fundamento da Administração ao utilizar o poder de polícia que também deverá se pautar, neste uso, nos princípios da legalidade, da razoabilidade ou da proporcionalidade.

O poder de polícia, portanto, é uma atribuição concedida à Administração Pública que a possibilita restringir direitos individuais opostos ao bem-estar social ou à evolução, bem como à própria segurança pública.

Neste viés o presente artigo faz uma breve abordagem da Administração Pública, em seu contexto originário e conceitual. Em seguida, apresenta como objeto o Poder de Polícia. A pesquisa tem como objetivo desenvolver e apresentar as principais perspectivas do poder de polícia, através da exegese do seu panorama histórico e conceitual, as suas espécies, 
características, princípios e limitação, cuja abordagem metodológica é de natureza qualitativa, por entendê-la como um instrumento de análise do tema pesquisado. Trata-se de um estudo de revisão bibliográfica, de método dedutivo, de caráter exploratório, descritivo que, em sede de conclusão, apresenta os benefícios do poder de polícia para o bem-estar coletivo.

\section{A ORIGEM DA ADMINISTRAÇÃO PÚBLICA}

O Estado brasileiro, tradicionalmente instituído nos moldes burocráticos de administração, com o fenômeno mundial da globalização, aliado a diversas inovações tecnológicas, deu passos no sentido de voltar seus esforços para o atendimento de demandas sociais, o que, consequentemente, começou a ser questionado o exercício absoluto do poder de polícia, visto que enquanto as demandas sociais aumentavam, o poder do governo diminuía.

O modelo de Estado e o aparelho da máquina administrativa, inseridos nesse contexto, necessitaram de uma intensa reformulação. À vista disso, surgiu o modelo gerencial de Administração Pública, com a finalidade de ultrapassar o tradicional modelo burocrático de gestão, diante da aquisição de instrumentos que buscam a efetividade administrativa e, também, a concretização dos anseios da sociedade, isto é, a competência para a gestão transforma-se no centro de debate da Administração Pública, acrescido com as relevantes modificações econômicas, a privatização, entre outros.

De tal modo, a modificação mundial emanada com a globalização concorreu para que a administração pública tivesse um impulso de qualidade positiva. Em muitos países ocorreram diversas revoluções, no Brasil, em especial, ocorreu a travessia da década de 80 que não acompanhou tal processo. Em oposição a este pensamento, a Constituição Federal de 1988 direcionava a Administração ainda ao antigo modelo burocrático, mas ocorreu um latente avanço, entre eles na esfera dos direitos sociais e individuais. Em outras palavras, quando se institui uma Assembleia Constituinte, busca-se modificar a situação vigente até então. A Lei Maior, em sua origem, obstou os pressupostos da administração gerencial, como exemplo o "regime jurídico único" aplicado aos servidores públicos da administração pública direta e, também, das autarquias e das fundações públicas de direito público, inseridas na Administração indireta, objeto da descentralização administrativa.

Em outro viés, possibilitou a concretização ou elaboração de benefícios, entre eles, a título de ilustração: a possibilidade de aposentadoria sob o recebimento de remuneração 
integral, independendo do tempo laboral prestado de forma direta ao Estado (PEREIRA; SPINK, 2003. p. 247).

Em 1995, surgiu a discussão acerca da reforma do aparelho estatal. No mais, eis que surge a reforma administrativa:

\begin{abstract}
Apesar de aparecer de maneira bastante tímida na campanha presidencial de 1994 e de não contar com o apoio entusiástico do grupo governamental mais forte (na Casa Civil, Clóvis Carvalho; na Fazenda, Pedro Malan; e no Planejamento, José Serra), o tema da reforma administrativa foi sendo colocado na agenda nacional devido à habilidade do ministro Bresser Pereira), que comandava o Ministério da Administração e Reforma do Estado (MARE) (Torres, 2004, p. 171).
\end{abstract}

Houve a elaboração do Ministério da Administração e Reforma do Estado, porém, a reforma administrativa, à época, não era prevalente ao Governo de Fernando Henrique Cardoso. Isto posto, em novembro de 1995, no Brasil, foi criado o Plano Diretor da Reforma do Aparelho do Estado com a proposta de admissão do modelo gerencial, para extinguir atividades de naturezas clientelistas e patrimonialistas executadas até então pelo modelo burocrático. Contudo, este plano diretor teve grandes obstáculos diante da não aderência da classe mais influente do governo e, mais, pela forte pressão opositiva dos servidores.

Assim, a reforma administrativa ganhou maior destaque perante a revisão do marco legal, entre as mais importantes, realça-se a aprovação da Emenda Constitucional no 19, de 04 de junho de 1998, que estabeleceu a adesão do Princípio da Eficiência pela Administração Pública brasileira, que trouxe ao aparelho estatal inúmeras transformações, como a reserva (percentual) de cargos em comissão para servidores de carreira; contrato para os órgãos públicos; a promoção ao controle social sobre a Administração Pública, entre outras.

\title{
3 EVOLUÇÃO HISTÓRICA DO PODER DE POLÍCIA
}

A origem do poder de polícia, bem como os seus pressupostos de natureza filosófica, se destinam a possibilitar a atuação do Estado Democrático de Direito, sem olvidar especificamente que esta ferramenta não se prende apenas ao aspecto punitivo, mas também ao preventivo, que estabelece ações de gestão de interesse público, atribuídas à Administração Pública. 
A expressão "polícia" tem origem na Grécia, mais especificamente no termo "politeia”, definida para determinar todas as funções das polis ${ }^{3}$, as Cidades-Estados. Durante a Antiguidade e a Idade Média, o termo "politeia" compreendia o conjunto político do Estado ou da cidade. Ao longo do período feudal, o poder "jus politiae" era pertencente ao príncipe, que possuía a competência para determinar, quanto necessário, para a adequada ordem social sujeita ao Estado, em oposição à boa ordem de cunho moral e religioso, que cabia exclusivamente à autoridade eclesiástica.

$\mathrm{O}$ auge do Poder de Polícia ocorreu na primeira fase da Idade Moderna, durante o Estado Absolutista. À época, a polícia estabelecia toda a função pública interna constituída na opção de reger tudo que estava submetido ao controle do Estado. No mais, o Estado de Direito emergiu durante a segunda fase da Idade Moderna, na qual ao Poder de Polícia foram impostas determinadas limitações. Dessa forma, diante deste condicionamento percebe-se um Estado Liberal que fornece salvaguarda às liberdades individuais, limitando-se em uma polícia que preza a segurança. Dessarte, no prelúdio do século XVIII, a polícia define a atuação pública interna, momento no qual o seu sentido amplo de polícia abre margem à ideia de Administração Pública. A noção de "polícia" limita-se sob a latente interferência das convicções da Revolução Francesa, acerca da valorização dos direitos individuais e dos ideais de Estado de direito e Estado liberal.

$\mathrm{Na}$ visão de conceito clássico de Di Pietro o poder de polícia é compreendido como um poder: "[...] ligado à concepção liberal do século XVIII, o poder de polícia compreendia a atividade estatal que limitava o exercício dos direitos individuais em benefício da segurança" (2014, p. 124, grifo da autora).

Corroborando com tal pensamento, a função do poder de polícia também se expandia em ações que limitavam a atuação dos direitos individuais em favor à efetiva segurança da localidade, isto é, em benefício do bem-estar social.

Deste modo, a Polícia começa a ser enxergada como parcela das funções/ações da Administração Pública, para manter o equilíbrio e a salubridade da população e preservar a ordem pública, econômica e social. Progressivamente, a utilização do termo "polícia" deixou de ser usado de forma isolada, nomeando-a como parte da função da Administração. Surgiu, assim, de início o termo polícia administrativa na França, em oposição à polícia judiciária.

\footnotetext{
${ }^{3}$ É o modelo das antigas cidades gregas, do período arcaico até o período clássico, perdendo a sua relevância com o domínio romano.

Revista de Direito Administrativo e Gestão Pública | e-ISSN: 2526-0073 | Salvador | v. 4 | n. 1 | p. 76 - 97 | 
O termo "Poder de Polícia" foi utilizado incialmente durante a Suprema Corte Americana, durante o julgamento do caso Brown x Maryland ${ }^{4}$, de 1827, que referenciava ao Estado-Membros de editar leis condicionantes de direitos, em prol da efetividade da garantia do interesse coletivo (DI PIETRO, 2014).

A partir de então, firmou-se, no ordenamento jurídico brasileiro, o uso deste termo para conceituar uma forma de poder da Administração Pública, além de impor limites ao interesse público.

Seguindo esta linha de raciocínio, Hely Lopes Meirelles, preleciona que o poder de polícia surge da necessidade do Estado que

[...] busca não só preservar a ordem política senão também estabelecer para a vida de relações dos cidadãos aquelas regras de boa conduta e de boa vizinhança que se supõem necessárias para evitar conflito de direitos e para garantir a cada um gozo ininterrupto de ser próprio direito, até onde for razoavelmente compatível com o direito dos demais (MEIRELLES, 2016, p. 154-155).

Cabe, por oportuno, acrescentar que no Brasil foi adotado o modelo medieval português. Este modelo adotou as atividades denominadas como "policia" e "judicatura", que se complementavam. Mais precisamente, em 1842, as atuações da polícia administrativa e judiciária, que estavam sob a gestão do Ministro da Justiça, foram regulamentadas ${ }^{5}$. Em 1871, por sua vez, com a Lei 2.033, ocorreu a separação das competências da justiça e de Polícia.

Estas premissas demonstram que o poder de polícia, portanto, é primordial para a manutenção da sistemática da sociedade.

\section{NATUREZA CONCEITUAL DO PODER DE POLÍCIA}

No Brasil, o poder de polícia em seu panorama conceitual assemelha-se à ideia Norte Americana (Police of Power), ou seja, o poder de polícia corresponde à Administração

\footnotetext{
${ }^{4}$ Brown v. Maryland (1827), foi um repercurssivo caso da Suprema Corte dos Estados Unidos, no qual interpretou, pela primeira vez, as Cláusulas de Importação-Exportação e Comércio da Constituição dos EUA, com a finalidade de obstar a tributação discriminatória pelos estados em oposição aos objetos importados após a importação, em vez de somente no momento da importação. Nesse interim, o estado de Maryland aprovou uma lei que obrigava que importadores de produtos estrangeiros adquirissem uma licença para vender seus produtos. Brown, na época, foi acusado por esta lei e apelou. O juiz John Marshall deferiu a opinião do Tribunal, declarando que o Estatuto de Maryland infrigia veemente as cláusulas de importação e exportação em que a lei federal era suprema. Ele aduziu que o poder de um estado para taxar bens era inaplicável caso eles permanecessem em seu "pacote original". Um imposto de licença sobre o importador era essencialmente o mesmo que um imposto sobre uma importação em si. Apesar de discutir o caso para Maryland, o futuro juiz Roger Taney admitiu que $o$ caso foi decidido corretamente. (fonte: https://supreme.justia.com/cases/federal/us/25/419/case.html)

${ }^{5}$ Por meio do regulamento $\mathrm{n}^{\circ} 20$. 
Pública que utiliza meios para estabelecer/impor restrições ao direito de liberdade individual pátrio, com vistas à prevalência do interesse coletivo sobre o individual. Logo, o Estado possui a prerrogativa de aplicar sanções nos casos em que o indivíduo conteste as normas que lhe são impostas.

Em reforço ao entendimento acima exposto, Otto Mayer conceitua que: "la polícia es la atividad del Estado que tiene por fin la defensa del buen orden de la cosa publica, mediante los recursos del poder de la autoridad, contra lsa pertubaciones que las existencias idividuales pueden ocasionar" ${ }^{\prime 6}$ (1950, p. 08).

Di Pietro apresenta uma definição mais simplificada e moderna sobre o Poder de Polícia é “[...] adotado no direito brasileiro [...] é a atividade do Estado consistente em limitar o exercício dos direitos individuais em benefício do interesse público" (2014, p. 124, grifo da autora).

Decerto, o Estado é detentor de poderes políticos emanados pelo Poder Executivo, pelo Poder Legislativo e pelo Poder Judiciário, com requisitos característicos específicos e competências para executar atividades constitucionais. Os poderes, ademais, também possuem autoridade administrativa que emerge por meio de atos da Administração Pública e, efetivamente, se concretiza em consonância com as exigências do serviço público decorrentes dos anseios sociais.

Por estas definições, evidencia-se que o poder de polícia resulta numa função dual de atividade/poder do Estado, que através de diversos instrumentos legais, objetiva manter a ordem social e coletiva. Isto é, busca evitar a supremacia do interesse do particular sobre o coletivo, para inibir violações, abusos, como a utilização imprópria da propriedade, o uso de atividades evasivas à coletividade.

A finalidade, portanto, é promover o equilíbrio da relação social, sanando e impedindo conflitos surgidos durante a execução dos direitos dos cidadãos entre si. Neste cenário, o poder de polícia surge como um complexo de funções de polícia que integram muitos órgãos da Administração Pública, utilizando-os como ferramentas de proteção dos interesses especiais comuns.

\footnotetext{
${ }^{6}$ Tradução: "A polícia é a atividade do Estado, que tem como objetivo a defesa da boa ordem da coisa pública, através dos recursos do poder da autoridade, contra as perturbações que as existências individuais podem ocasionar".
} 
Todas essas atividades são executadas por órgãos incumbidos da função de impor limitações à população, mas que correspondam concretamente ao interesse geral, sempre agindo com o fito de beneficiar o bem coletivo.

O poder de polícia pode ser enxergado na perspectiva de duas óticas, quais sejam: uma em sentido amplo e outra ótica em sentido estrito. O primeiro sentido corresponde a todas as funções estatais condicionantes do exercício da liberdade e da propriedade e determina temas concernentes às atividades administrativas e legislativas, esta sob o modelo de lei geral e abstrata. O segundo sentido, por sua vez, relaciona-se às limitações implementadas pelo Poder Executivo, na busca de obstar atos individuais que violem interesses coletivos, independendo de seu modelo geral, abstrato ou concreto (MELLO, 2010).

Já Mello (2010) divide o poder de polícia em duas atividades: a negativa e a positiva. Na visão negativa, o autor entende o poder como uma atividade que estabelece uma privação ao indivíduo, ou seja, sempre impõe uma obrigação de não fazer, embora haja a determinação de uma obrigação de fazer. Já na que o determina como uma atividade positiva, o autor elucida que a função concebida pelo poder de polícia beneficia os indivíduos, de forma isolada ou conjuntamente. À vista disso, a Administração executa uma função material que beneficia o indivíduo ${ }^{7}$.

Para Meirelles, o Poder de polícia é "[...] a faculdade de que dispõe a Administração Pública para condicionar e restringir o uso e gozo de bens, atividades e direitos individuais, em benefício da coletividade ou do próprio Estado" (2016, p. 152). Este poder, dessa forma, possibilita que a Administração Pública possa impor limites às liberdades fundamentais em benefício do bem-estar social, respeitando sempre os ditames legais.

Já para Cretella Jr. (2000), o poder de polícia é uma opção do Estado que possui natureza discricionária em limitar a liberdade do particular ou do coletivo, com a finalidade de beneficiar o interesse público.

Ultrapassadas as conceituações doutrinárias, cabe destacar os principais fundamentos legais acerca do poder de polícia. Com efeito, este poder é imperioso para a Administração Pública, se repartindo entre todas as demais esferas administrativas, seja da União, dos Estados e dos Municípios. Posto isto, é sabido que a definição deste poder integra relevante parcela da legislação brasileira, entre elas o Código Tributário Nacional, que dispõe:

\footnotetext{
${ }^{7}$ Como exemplo, tem-se quando a Administração realiza o serviço de transporte coletivo, determinando limites às condutas individuais.

Revista de Direito Administrativo e Gestão Pública | e-ISSN: 2526-0073 | Salvador | v. 4 | n. 1 | p. 76 - 97 | 
Art. 78 Considera-se poder de polícia a atividade da Administração Pública que, limitando ou disciplinando direito, interesse ou liberdade, regula a pratica de ato ou abstenção de fato, em razão de interesse público concernente à segurança, à higiene, á ordem, aos costumes, a disciplina da produção e do mercado, ao exercício de atividades econômicas dependentes de concessão ou autorização do Poder Público, à tranquilidade pública ou ao respeito à propriedade e os direitos individuais ou coletivos (BRASIL, 1966).

Nesse sentido, sabe-se que o Poder Legislativo edita leis e também aquelas que validam o poder de polícia, com o intuito de limitar as ações inadequadas de cidadãos no exercício do direito de propriedade e de liberdade. A Administração Pública tem, entre seus objetivos, aplicar estas leis de ofício aos casos concretos. Assim, a Administração Pública, utilizando-se de sua supremacia geral, controla e fiscaliza os atos dos cidadãos perante tais leis. Outro relevante fundamento da polícia administrativa consubstancia-se na proteção da ordem pública.

A Carta Magna de 1988 estabelece no seu art. 5, incisos IV, XIII, XV e XXII, direitos referentes à utilização, gozo e disposição da propriedade, além de tratar do exercício da liberdade. Cabe, pois, pontuar que a execução desses direitos deve estar em equilíbrio como bem-estar coletivo ou com o próprio interesse público. Limitar a utilização de tais direitos, impede a violação de direitos de terceiros, bem como assegura a colimação do interesse da coletividade.

Como exemplos de poder de polícia têm-se: a realização da concessão de alvará de construção; a aplicação de multa por construção irregular ou por ultrapassar os limites de velocidade; a demolição de casa construída em obra pública, a concessão de licença de instalação, entre outros.

\subsection{As Espécies de Poder de Polícia: Administrativo e Judiciário}

Transpostas as mais relevantes definições (doutrinárias e legais) de poder de polícia, neste momento resta oportuno realizar a descrição acerca da distinção entre a polícia administrativa e a polícia judiciária.

Dessa forma, a seguir são instituídos os principais requisitos conceituais e a preponderância de cada espécie.

\subsubsection{O Poder de Polícia Administrativa}


A polícia administrativa incide sobre funções, bens e direitos dos indivíduos. A Administração, por meio desta, busca a manutenção da ordem pública geral, proibindo, de forma preventiva, eventuais violações às leis, inexistindo quaisquer sanções que culminem em detenção ou reclusão do cidadão. É executada por órgãos da Administração Pública, a exemplo do DETRAN e do IBAMA.

A polícia administrativa, como já mencionado, pode agir de forma preventiva, bem como de forma repressiva. Contudo, independente da forma aplicada, a finalidade precípua é obstruir que a conduta do indivíduo ocasione danos para a coletividade.

Tal poder se exterioriza por meio de atos normativos definidos como concretos e específicos, através de: a) atos normativos e de abrangência geral, assim, pela lei constituemse as restrições administrativas à atuação dos direitos e das ações individuais, podendo ocorrer por Decretos, Resoluções, Portarias, Instruções; b) dos atos administrativos e também de procedimentos materiais para aplicação da lei ao caso concreto, através da inserção de medidas com caráter dual (repressivo e preventivo), todas com o escopo de obrigar o infrator ao fiel cumprimento da lei.

Mazza evidencia que a polícia administrativa:

[...] tem caráter predominantemente preventivo, atuando antes da infração ocorrer, para evitá-la, submetendo-se essencialmente às regras do Direito Administrativo. No Brasil, a polícia administrativa é associada ao chamado policiamento ostensivo, sendo realizada pela Polícia Militar (2015, p. 347).

A polícia administrativa tem por objetivo último atentar-se à consequência da conduta do indivíduo na sociedade, salvaguardando, assim, a cada cidadão a qualidade de sobrevivência, sem que estes violem direitos ou causem lesões a outros indivíduos.

Silva esclarece que o exercício da polícia administrativa é dual, ou seja, preventivo e repressivo, apresentando exemplos quanto à fiscalização de produtos expostos à venda por comerciantes:

A polícia administrativa tanto pode agir preventivamente (orientando os comerciantes sobre o risco de expor a venda produtos deteriorados ou impróprios para o consumo), como pode agir repressivamente (apreendendo os produtos vencidos dos estabelecimentos comerciais). Nas duas hipóteses a sua função é impedir que o comportamento do indivíduo cause prejuízos para a coletividade (SILVA, 2006, p. 1). 
Constata-se, assim, que o poder de polícia administrativa busca assegurar os valores: de segurança, ordem, tranquilidade, higiene e saúde públicas; estéticos e artísticos; históricos e paisagísticos; de riquezas naturais; de moralidade pública; de economia popular e etc.

\subsubsection{O Poder de Polícia judiciária}

A polícia judiciária é a função exercida por organismos de natureza repressiva e ostensiva, com o objetivo de limitar a atividade de indivíduos infratores, utilizando-se da instrução policial criminal e da lei penal. Este tipo de polícia recai sobre os indivíduos, sendo executado por órgãos especializados, entre eles a polícia civil e a polícia militar.

Assim, a polícia judiciária auxilia o Poder Judiciário, no momento de aplicar a lei ao caso concreto, com o fim da efetiva execução de sua função jurisdicional. Neste viés, a polícia judiciária pode aplicar sanção que resulte em detenção ou reclusão ao cidadão.

Como exemplo, estabelece a Constituição Federal de 1988, em seu art. 144, que a segurança pública é dever do Estado. Porém um direito e responsabilidade de todos, e é exercida através da polícia federal, polícia rodoviária federal, polícia ferroviária federal, polícias civis, polícias militares e corpos de bombeiros militares.

Oportuno destacar, à polícia militar compete a função da polícia judiciária, além da polícia administrativa, aplicando esta última no momento de imposição de multa de trânsito ou apreensão de mercadorias irregulares.

Para Mazza a "[...] atuação da polícia judiciária tem natureza repressiva, agindo após a ocorrência do crime para apuração da autoria e materialidade" (2015, p.347). Nesse sentindo, a polícia judiciária age, em regra, de forma repressiva quando controla, persegue indivíduos infratores ou através da realização de prisões à indivíduos praticantes de delitos penais. Já a atuação preventiva da polícia judiciária consiste no exercício da fiscalização policial de rotina em localidade de risco ou realiza prisões como medidas de prevenção, para evitar eventuais práticas nocivas à sociedade.

Portanto, o meio de distinção entre o poder de polícia administrativa e o poder de polícia judiciária está calcado em que a primeira age de forma preventiva diante dos fatos que acontecem, que mesmos lícitos, podem ser objeto de restrição. Já polícia judiciária é aquela que instrui o Judiciário na apuração de eventos tipificados penalmente, provando a autoria, motivos e etc.

Milita deste pensamento Medauar ao dizer que: 
A polícia administrativa ou poder de polícia restringe o exercício de atividades lícitas, reconhecidas pelo ordenamento como direitos dos particulares, isolados ou em grupo. Diversamente, a polícia judiciária visa a impedir o exercício de atividades ilícitas, vedadas pelo ordenamento; a polícia judiciária auxilia o Estado e o Poder Judiciário na prevenção e repressão de delitos (2004, p.392).

À vista disso, o poder de polícia administrativa busca tolher a desordem social, na medida em que o poder de polícia judiciária visa a responsabilização penal.

\section{CARACTERÍSTICAS DO PODER DE POLÍCIA}

O poder de polícia, repita-se, decorre da ordem de obrigação de não fazer, isto é, a Administração Pública utiliza este poder no intuito de coibir a ocorrência de danos à sociedade. Dessa forma, a Administração utiliza o poder de polícia tanto através da aplicação multa para àquele que afronta o ordenamento legal, tanto quanto limita o exercício de atos a determinadas regras. Assim sendo, atribui-se a este poder um caráter negativo.

Ao tratar da natureza negativa atrelada ao poder de polícia, Sundfeld suscita que:

A ideia de poder de polícia foi cunhada para um Estado mínimo, desinteressado em interferir na economia, voltado, sobretudo, à imposição de limites negativos à liberdade e à propriedade, criando condições para convivência dos direitos. Daí haver-se definido o poder de polícia como imposição ao particular do dever de abstenção, de não fazer. Mas, modernamente, a interferência estatal se intensificou e mudou de qualidade, por conta da superação do liberalismo clássico. O Estado Social, mais do que pretender a harmonização dos direitos individuais, impõe projetos e serem implementados coletivamente: o desenvolvimento nacional, a redução das desigualdades, a proteção do meio ambiente, a preservação do patrimônio histórico (1997, p. 14).

Contudo, na busca pela garantia dos interesses sociais e coletivos, à Administração Pública dispõe de determinadas prerrogativas, na medida em que ela tem a função de limitar as ações dos direitos individuais, restringindo-os aos interesses coletivos.

\subsection{Discricionariedade}

A discricionariedade concede ao agente público certa margem de liberdade para decidir em casos determinados, na medida em que o legislador nem sempre poderá estabelecer os fatos possíveis de ocorrer. Assim, diante desse viés, a Administração Pública deve decidir per si o melhor momento, a melhor forma e a sanção mais adequada a ser 
aplicada em certa situação. O poder discricionário surge diante da necessidade da Administração resolver o conflito adequadamente ante o caso concreto.

No entanto, existem casos em que a lei determinará as medidas que devem ser assumidas pela Administração em certos casos sem o uso, contudo, da discricionariedade, culminando na vinculação do poder à lei escrita. Logo, o Poder discricionário na polícia administrativa existe em determinados casos. Contudo, em certas situações, aplicar-se-á o poder vinculado (DI PIETRO, 2014).

Nessa linha de pensamento, Di Pietro corrobora:

Como todo ato administrativo, a medida de polícia, ainda que seja discricionária, sempre esbarra em algumas limitações impostas pela lei, quanto à competência e à forma, aos fins e mesmo com relação aos motivos ou ao objeto; quantos aos dois últimos, ainda que a Administração disponha de certa dose de discricionariedade, esta deve ser exercida nos limites traçados pela lei $(2014$, p.129, grifo da autora).

Nesse sentido, Batista Junior preleciona que:

A polícia é um setor só parcialmente controlado pela lei, porque nunca foi possível cingi-la completamente na legalidade, diante das manifestações multímodas das condutas individuais e da vida social, que forçam a que se deixe certa margem de liberdade de atuação (2001, p. 79).

O poder discricionário, assim, é uma das prerrogativas do poder de polícia na Administração Pública, em que ao agente público é concedida a faculdade de agir em conformidade com a conveniência e oportunidade, dentro dos ditames da lei.

\subsection{Autoexecutoriedade}

À Administração Pública é dada a prerrogativa de liberdade quanto à tomada de decisões, as quais não requerem qualquer submissão ou auxílio do magistrado. Ademais, para exigir uma obrigação ao administrado, a Administração estabelece diretamente a ele medidas ou sanções de polícia administrativa, para impedir o cometimento ou eventuais atividades contrárias e não benéficas ao bem-estar social.

Para Di Pietro, a autoexecutoriedade é “[...] a possibilidade que tem a Administração de, com os próprios meios, pôr em execução as suas decisões, sem precisar recorrer previamente ao Poder Judiciário" (2014, p.127).

Para boa parcela doutrinária, este atributo divide-se em: a exigibilidade e a executoriedade. A exigibilidade consiste na viabilidade da Administração Pública em adotar 
decisões de execução. Por este atributo, então, a Administração utiliza métodos indiretos de coação. Já a executoriedade é a faculdade da Administração de executar o poder de forma direta, implementando-a mesmo diante da necessidade do uso de coerção para exigir que o administrado cumpra determinadas decisões por ela emanadas (MELLO, 2010).

Ainda para Mello, a executoriedade “[...] é caracterizada pela utilização de meios diretos de coerção, pois, por meio dela o administrado é compelido materialmente a acatar a determinação do Estado, fica impedido fisicamente de continuar a desobedecer a norma jurídica" (2010, p.777).

Portanto, a executoriedade surge quando a Administração obriga ao administrado o fiel cumprimento da regra, sob pena de perder o exercício de seu direito ou da atividade objeto de ilegalidade. Como exemplos têm-se os atos de cassação de licença para dirigir, a interdição ou a demolição de uma obra, entre outros.

É de se ressalvar que estes dois atributos, a exigibilidade e a executoriedade são requisitos dos atos administrativos que não necessitam de apreciação judicial prévia. Nesse sentido, Meirelles afirma que "Exigir-se previa autorização do Poder Judiciário equivale a negar-se o próprio poder de polícia administrativa, cujo ato tem que ser sumário, direto e imediato, sem as delongas e as complicações de um processo judiciário prévio” (2016, p. 160).

De fato, a Administração é compreendida como uma atuação estatal e tem por escopo buscar o bem-estar social. Contudo, podem ocorrer casos contrários às decisões pretendidas pelos administrados, que estes entendam como ofensivas, o que culmina no direito do particular de recorrer ao Poder Judiciário, por meio da impetração dos remédios processuais conhecidos como o mandado de segurança e o habeas corpus.

\subsection{Coercibilidade}

O atributo da coercibilidade na Administração Pública possui interpretação semelhante à autoexecutoriedade, e corresponde à atribuição de coação aos atos administrativos, ou seja, caso ocorra necessidade, pode usar a força coercitiva, para efetivar os interesses da coletividade. Quer dizer, os atos administrativos são indispensáveis e exigem o seu cumprimento à todos que estão ao seu redor mesmo que tal fato viole o interesse individual, visto que a este prevalece o interesse coletivo (DI PIETRO, 2014). 
Este atributo está intimamente correlacionado à coação expressa nos meios de natureza autoexecutórias da Administração Pública, sendo, por tal motivo, inseparável da autoexecutoriedade.

Como outro atributo do Poder de Polícia, Di Pietro adota a indelegabilidade para pessoas jurídicas de direito privado “ [...] com base no argumento de que, em se tratando de atividade típica do Estado, só pode ser por este exercida" (2014, p.129), o que vem sendo reconhecido pela jurisprudência, até pelo Supremo Tribunal Federal.

\subsection{Indelegabilidade}

Este tema está ainda em debate no campo doutrinário em relação a possibilidade de delegação do poder de polícia para entidade privada, na medida em que, para alguns doutrinadores, o poder de polícia apenas poder ser executado por órgão da Administração Pública, na circunstância de Poder Público, obstando, assim, ser exercido por órgãos paraestatais, como empresas públicas, sociedades de economia mista e outras entidades que explorem atividade econômica.

Por outro lado, alguns doutrinadores como Mello (2010), defendem a possibilidade de delegação para o particular de determinados atos materiais que precedem ou são sucessivos à atos jurídicos de polícia, a exemplo os fotossensores operados por empresas privadas e que acusam o excesso de velocidade e a contratação de empresa privada para demolição de imóvel, desde que observado o devido processo legal, respectivamente.

\section{SISTEMA PRINCIPIOLÓGICO DO PODER DE POLÍCIA}

Os princípios são definidos como um conjunto de normas de conduta que devem ser obedecidos por um indivíduo ou uma instituição. Princípio relaciona-se ao início de algo e a expressão possui origem do latim princip̌̆um, que significa "origem", "causa próxima", ou "início". Princípios, portanto, são as bases da norma, o seu fundamento em cerne, o local no qual a norma encontra sustentação para pensar a sua legitimação.

Para Marcelo Alexandrino e Vicente Paulo, os princípios

[...] estabelecem as suas diretrizes, conferem a ele um sentido lógico, sistêmico e harmonioso, o que possibilita uma adequada compreensão de sua estrutura. Os princípios - que podem ser expressos ou implícitos determinam o alcance e o sentido das regras de um dado subsistema do ordenamento jurídico, balizando a interpretação e apropria produção normativa (2017, p. 226). 
Em relação ao sistema principiológico que norteia o poder de polícia, Vitta (2010) discorre que o poder de polícia administrativa extrai seu fundamento no princípio da supremacia do interesse público sobre o particular, dispondo para a Administração Pública o lugar do exercício de supremacia sobre os indivíduos, além de exercê-lo sobre todo o território, bens e atividades, nos ditames constitucionais e nas normas de ordem pública, em benefício à efetividade do interesse coletivo.

Os princípios orientadores do poder de polícia, portanto, são: o princípio da supremacia do interesse público sobre o particular, o princípio da legalidade e o princípio da razoabilidade/proporcionalidade.

\subsection{O Princípio da supremacia do interesse público}

O princípio da supremacia do interesse público, embora não possua previsão legal expressa, se encontra implícito na Lei Maior e é adotado como o principal fundamento do poder de polícia, com o fim de efetivar a predominância do interesse público sobre o privado.

Di Pietro afirma que:

[...] quanto aos fins, o poder de polícia só deve ser exercido para atender ao interesse público. Se o seu fundamento é precisamente o princípio da predominância do interesse público sobre o particular, o exercício desse poder perderá a sua justificativa quando utilizado para beneficiar ou prejudicar pessoas determinadas (2014, p. 129).

Ocorre que as diversas manifestações da atuação do poder de polícia da Administração, decorrente da imposição de limites ao exercício das atividades privadas, beneficia a coletividade, e é um forte exemplo de prerrogativa da Administração Pública que produz grandes resultados para a garantia da supremacia do interesse público.

Dirley da Cunha Júnior (2018), ao tratar do tema, fala da verticalidade presente nas relações entre a Administração e os administrados. Para ele, existe, assim, uma desigualdade jurídica, na medida em que a posição de supremacia vertical da Administração, confere um privilégio à mesma. em uma situação de mando e autoridade em relação aos particulares, como exigência indispensável para a solução de interesses públicos em conflito.

Cabe enfatizar que o administrador que não perseguir o alcance da finalidade pública incorre em desvio de poder, sob a pena de nulidade do ato com todas os efeitos referentes às esferas civil, penal e administrativa. 


\subsection{O Princípio da legalidade}

$\mathrm{O}$ art. 37, caput, da Constituição Federal de 1988, estabelece que à Administração Pública se impõe a obediência “[...] aos princípios da legalidade, impessoalidade, moralidade, publicidade e eficiência” (BRASIL, 1988). Diga-se que entre outros, à Administração Pública cabe o respeito na execução dos seus atos, conforme previsão legal.

Dessa forma, a Constituição consagra o princípio pelo "qual ninguém é obrigado a fazer ou deixar de fazer alguma coisa a não ser em virtude da lei”. Em outra frente, o princípio da legalidade decorre daquilo que está prescrito expressamente em lei. Observandose ainda a legalidade, destaque-se que os princípios da moralidade e da impessoalidade interligam a atuação ou o ato administrativo ao interesse público.

No que concerne ao poder de polícia, com o surgimento do Estado de Direito o postulado da legalidade começou a ser empregado como fundamento não só para os administrados, como também para o Estado, culminando no seu caráter de assegurar as atividades da Administração Pública perante os administrados.

\subsection{O Princípio da proporcionalidade ou razoabilidade ${ }^{8}$}

Este postulado consiste na orientação do ato do poder público que deve ser exercido em conformidade com a adequação, a necessidade e a medida proporcional. A primeira noção, a adequação, corresponde à obrigatoriedade que tem a Administração Pública de usar meios acertados para efetivar as finalidades pretendidas. Já a necessidade cuida que a Administração Pública assuma medidas que resultem em menos restrições aos direitos dos administrados, para limitar excessos. Por sua vez, a proporcionalidade, em sentido estrito, determina que deve haver uma harmonia entre o fato que resultou no ato administrativo e a medida adotada pela Administração Pública, para o alcance dos fins perseguidos.

Isto posto, em observância ao princípio da proporcionalidade, não pode a atuação do poder de polícia ultrapassar o quanto exigido. É dizer que o ato deve ser razoável (não excessivo) no que tange ao resultado que se pretende adquirir.

Em seguimento, acerca dos parâmetros que balizam o desempenho estatal de polícia, Faria alerta que:

\footnotetext{
${ }^{8}$ Os princípios da Proporcionalidade e da Razoabilidade são comumente utilizados como sinônimos por boa parte da doutrina e dos tribunais brasileiros. A diferença básica entre ambos reside na questão etimológica: proporcionalidade (oriunda do direito germânico) e razoabilidade (do direito anglo-saxônico). 
O exercício do poder de polícia, para encontrar validade no ordenamento jurídico, deve observar a proporcionalidade entre a restrição imposta ao particular e o benefício social pretendido, e também a proporcionalidade entre o dano causado pelo infrator da norma administrativa e a sanção imposta ao agente. A desproporcionalidade no comportamento de polícia da Administração, quanto aos citados aspectos, implicam a nulidade do ato (2000, p. 208).

Nesta senda, Vitta preceitua:

O princípio da proporcionalidade dos meios aos fins infere que o poder de polícia não deve ir além do necessário para a satisfação do interesse público que visa proteger. A sua finalidade não é destruir os direitos individuais, mas, assegurar o seu exercício condicionando-o ao bem-estar social (2011, p.94).

Ademais, qualquer ato da Administração Pública que obrigue a limitação em sua liberdade de propriedade do administrado, sem haver indício de interesse público satisfeito, será definido como ilegal.

\section{A LIMITAÇÃo DO PODER DE POLÍCIA}

Conforme supracitado, o poder discricionário é definido, em regra, como característica primordial do poder de polícia, porém, em determinados casos, age de forma vinculada, em decorrência das restrições estabelecidas por lei (DI PIETRO, 2014).

Diante da utilização de medidas com caráter coercitivo para executar o poder de polícia administrativa, exige-se o respeito à proporcionalidade do meio empregado pelo Poder Público, visto que abrange a liberdade individual do cidadão.

Sobre este entendimento, Meirelles reafirma que "Os limites do poder de polícia administrativa são demarcados pelo interesse social em conciliação com os direitos fundamentais do indivíduo assegurados na Constituição da República” (2016, p. 157).

Contudo, para a adequada efetividade do poder de polícia administrativa sem extinguir os direitos individuais devem-se cumprir determinadas regras, quais sejam: a) a da exigência, pela qual o poder de polícia só deverá ser utilizado para obstar ameaças reais ou eventuais de perturbações ao interesse público; b) a da proporcionalidade, em que deve existir um equilíbrio entre a restrição ao direito individual e o dano a ser obstaculizado, e; c) a da eficácia, na medida em que se utiliza de ação amplamente satisfatória para o efetivo atendimento do interesse público (DI PIETRO, 2014). 
Feito estes apontamentos, cabe ressalvar que quando a polícia administrativa for atuar, deverá fazê-lo em cumprimento às liberdades públicas e aos direitos individuais previstos na Carta Constitucional, para não se tornar-se ilegítimo e desproporcional o ato emanado.

Outrossim, se este poder fosse ilimitado/absoluto, ter-se-ia um Estado Intervencionista, impedindo a efetividade da segurança e da ordem econômica e social.

\subsection{Abuso de Poder}

A expressão abuso é originária do latim abusu que significa "Uso mau, excessivo ou injusto: [...] Injustiça, desordem, excesso: [...] Abuso de direito, ação que consiste em ultrapassar os limites consignados ao exercício de um direito" como definido no Dicionário Online (2018, s/n).

No campo do Direito, este termo é utilizado ao se referir ao excesso de poder, abuso de poder, desvio de finalidade ou mau uso deste poder. Em se tratando da natureza humana, não raro, verificam-se atos praticados com excesso por agentes públicos, tanto agentes administrativos, quanto agentes políticos.

Para Meirelles o uso do poder é:

[...] Tratando-se de um poder discricionário, a norma legal que o confere não minudeia o modo e as condições da prática do ato de polícia. Esses aspectos são confiados ao prudente critério do administrador público. Mas, se a autoridade ultrapassar o permitido em lei, incidirá em abuso de poder, corrigível por via judicial. $\mathrm{O}$ ato de polícia, como ato administrativo que é, fica sempre sujeito a invalidação pelo Poder Judiciário, quando praticado com excesso ou desvio de poder (2016, p. 158).

Relevante destacar que o abuso de poder configura-se em ato ilegal, pois afronta o princípio da legalidade e dele decorrem as espécies: desvio de poder e excesso de poder. $\mathrm{Na}$ primeira, o que ocorre é a inadequação da finalidade do ato ou do interesse público, devidamente previstos na lei para aquele ato em especial. Na segunda espécie, o vício está na competência, ou seja, o agente público, eivado em sua competência, atua ultrapassando os seus limites definidos em lei ou pela Constituição (MELLO, 2010).

Em vista disso, para impedir o abuso de poder, devem-se impor limites aos meios de polícia, na medida em que este apenas pode ser exercido para atender ao interesse público. Dessa forma, a Administração Pública deve agir com cautela, não exercendo o poder de polícia por meios de instrumentos considerados excessivos para concretizar a finalidade 
almejada, uma vez que a desproporcionalidade do ato de polícia ou o seu excesso correspondem a abuso de poder.

\section{CONSIDERAÇÕES FINAIS}

Ante o exposto, demonstra-se que o poder de polícia atua como ferramenta limitadora das liberdades individuais. Com efeito, aos cidadãos devem ser concedidos os direitos à liberdade e à propriedade, dentre outros. Porém, devem estar limitados em prol do interesse da coletividade.

Inobstante citar que, perante os inúmeros conflitos sociais sofridos pelos cidadãos, o Estado busca interferir soberanamente na propriedade e nas atividades socialmente elaboradas, para manter e efetivar o bem coletivo. Logo, o interesse individual não pode superar o interesse coletivo, mas, a intervenção estatal, não deve ser opressiva na sua manutenção e sim, utilizar de mecanismos construtores da sociedade, que sanem ou minimizem conflitos que surjam entre o particular e a administração, promovendo assim a criação de uma Administração mais efetiva e eficaz.

Para atingir a finalidade de manter a ordem e o bem-estar social, a Administração Pública utiliza-se de determinados atos, entre eles, o do poder de polícia. Este pode consubstanciar-se na restrição de direitos dos cidadãos diante do alcance do interesse coletivo e, entre suas principais características ressalta-se a autoexecutoriedade, em que a Administração estabelece sua vontade por meio de medidas ou sanções adequadas para impedir a desordem social; a discricionariedade, na qual a Administração tem o poder-dever de decidir o meio, momento e sanção mais adequada à situação, porém, em certos casos a lei prevê a sua utilização e está pré-definida pelo legislador, demonstrando assim, nesse momento o uso do poder vinculado; a coercibilidade, como outra característica do poder de polícia, atrela o poder de polícia à força coercitiva, que pode tanto ser uma atividade negativa (obrigação de não fazer), quanto uma atividade positiva (dispõe benefícios ao indivíduo).

Foram analisados, também, os princípios essenciais ao poder de polícia, entre eles o da supremacia do interesse público, o da legalidade e, em especial, o princípio da proporcionalidade, no qual se demonstrou a necessidade de cautela e adequação na aplicação desse poder para benefício do interesse público e atendimento às exigências sociais.

Verificou-se, ainda, a limitação do poder de polícia, através da observação da forma, da finalidade e da competência, sob pena de se configurar em abuso/excesso/desvio de poder. 
Infere-se, então, que a restrição imposta pelo poder de polícia, aos direitos individuais do cidadão, culmina na harmonização da relação entre este e os interesses coletivos, como ferramenta precípua para o alcance e a efetividade do bem-estar social como um todo. Decerto, o homem vive em comunidade, o que obriga o Estado a empregar e concretizar o equilíbrio e a preservação da sociedade.

\section{REFERÊNCIAS}

ALEXANDRINO, Marcelo. PAULO, Vicente. Direito Administrativo Descomplicado. 19a edição - Rio de Janeiro: Método, 2011.

AURÉLIO, Buarque de Holanda Ferreira. Minidicionário da Língua Portuguesa. 3. ed. rev. e atual. Rio de Janeiro: Nova Fronteira, 1993.

BATISTA JÚNIOR, Onofre Alves. O Poder de polícia Fiscal. Belo Horizonte: Mandamentos, 2001.

BRASIL. Lei No 5.172, de 25 de outubro de 1966. Código Tributário Nacional. Disponível em: < http://www.planalto.gov.br/CCivil_03/leis/L5172.htm>. Acesso em: 10 mar. 2018.

Lei $\mathrm{N}^{\mathrm{o}} 2.033$, de 20 de setembro de 1871. Altera differentes disposições da Legislação Judiciaria. Disponível em:

http://legislacao.planalto.gov.br/legisla/legislacao.nsf/Viw_Identificacao/lim\%202.0331871?OpenDocument. Acesso em: 20 mar. 2018.

Constituição da República Federativa do Brasil. Promulgada em 05 de outubro de 1988. Disponível em:

<http://www.planalto.gov.br/ccivil_03/constituicao/constituicaocompilado.htm>. Acesso em: 10 mar. 2018.

CRETELLA JR., José. Direito administrativo brasileiro. 17. ed. Rio de Janeiro: Forense, 2000.

CUNHA JÚNIOR, Dirley da. Curso de Direito Constitucional. 12 ed, Salvador: JusPodium, 2018.

DI PIETRO, Maria Sylvia Zanella. Direito administrativo. 26. ed. São Paulo: Atlas, 2013.

FARIA, Edimur Ferreira de. Curso de direito administrativo positivo. 3. ed. rev. atual. e ampl. Belo Horizonte: Del Rey, 2000.

MAYER, Otto. Derecho Administrativo Alemán. Ed. Depalma, Buenos Aires, 1950.

MAZZA, Alexandre. Manual de direito administrativo. 5.ed. São Paulo: Saraiva, 2015. 
MEDAUAR, Odete. Direito administrativo moderno. 4. ed. São Paulo: Revista dos Tribunais, 2004.

MEIRELLES, Hely Lopes. Direito administrativo brasileiro. 25. ed. São Paulo: Malheiros, 2007.

MELLO, Celso Antônio Bandeira de. Curso de direito administrativo. 27. ed. São Paulo: Malheiros, 2010.

PEREIRA, Luiz Carlos Bresser; SPINK, Peter. Reforma e Administração Pública Gerencial. 5. ed. Rio de Janeiro: Editora FGV, 2003.

SILVA, Flávia Martins André da. O poder de polícia. Academia Brasileia de Direito. (03.11;2006). Disponível em: <http://www.abdir.com.br/doutrina/ver.asp?art_ $\mathrm{id}=\&$ categoria $=>$ Acesso em $: 30$ de outubro de 2015 .

SUNDFELD, Carlos Ari. Direito administrativo ordenador. $2^{\circ}$ Tiragem, São Paulo: Malheiros, 1997.

TORRES, Marcelo Douglas de Figueiredo. Estado, democracia e administração pública no Brasil. Rio de Janeiro: Editora FGV, 2004.

VITTA, Heraldo Garcia. Poder de polícia. São Paulo: Malheiros Editores, 2010. (Coleção temas de direito administrativo). . Soberania do Estado e poder de polícia. Coleção 28. São Paulo: Malheiros, 2011. 